\title{
Reciprocal Learning: Academic Supports in Middle and Secondary Schools
}

\author{
Kaleb Lo Stropkovics \\ University of Windsor
}

\begin{abstract}
This paper addresses the student support systems available in Chinese schools, with reference to those available in Canadian schools, in order to understand the most effective foundations for academic success and student motivation. The focus of educational support within Chinese and Ontario schools is rooted around times of high-stress exams, such as the Senior High School Entrance Exam (Zhongkao, 中考) and the National Higher Education Entrance Exam (Gaokao, 高考) in China, and the Education Quality and Accountability Office (EQAO) Literacy Exam and the Canadian Achievement Tests (CAT) in Ontario. I explore the available means through which schools provide guidance and additional support for students throughout the grades leading up to major examinations. This inquiry involves observation of various Chinese classrooms, research of literature examining stress levels and academic success, and observations of school programs and guidance facilities within the schools and communities.
\end{abstract}

\section{Background}

This paper explores the academic expectations of students balanced with the available mental health support agents within the school community. The purpose of the research project is to examine traditional practices and educational support within Chinese school systems in relation to student-life and academic success, in comparison to those in Canadian school systems. This project is contextualized in Shijing Xu and Michael Connelly's (2017) Social Sciences and Humanities Research Council (SSHRC) Partnership Grant Project: Canada-China Reciprocal Learning in Teacher Education and School Education (2013-2020). The originality of this project derives from the principle of reciprocal learning between the Canadian and Chinese school systems (Xu, 2011, 2017; Xu \& Connelly, 2008). According to Xu and Connelly (2017), the overall goal of the SSHRC Partnership Grant Project is to compare and contrast Canadian and Chinese education in such a way that the cultural narratives of each provide frameworks for understanding and appreciating 
educational similarities and differences. The overall goal of the partnership centers on reciprocal learning in teacher education and school education between Canada and China.

\section{Research Questions}

This research addresses the question: what preparation techniques and support do educational institutions make available for students in high-stress settings? Sub-questions include: (a) how do the support systems and national examinations in China (Beibei, Chongqing) compare to those within Canadian (Windsor, Ontario) institutions? and (b) what mental health supports are made available for students in the school setting?

\section{Literature Review: Support in Chinese Schools}

In China, two tests exist at set intervals, which determine the academic futures of students: a) the Senior High School Entrance Exam (Zhongkao, 中考) and b) the National Higher Education Entrance Examination (Gaokao, 高考). Both tests produce immense academic, and consequently, sociological pressures as they "are considered as the two most significant public examinations for students in China" (Chen, Fan, Cheung, \& Wu, 2018, p. 292). Both examinations are notoriously important in terms of future success and are seen as "gateway[s] to future life outcomes" (Sargent, Kong, \& Zhang, 2014, p. 98). In terms of academically-gifted students who may be victims to the anxiety of maintaining academic excellence, Chen, et al. (2018) acknowledge how "Chinese society places an extraordinarily high value on education; as a result, students are expected to pursue high scores in all the examinations in order to be admitted into good secondary schools or top universities" (p. 292). Poor performance on either test results in a lower level of funding or steaming of the student into a vocational school. As is the case in Canada, postsecondary education is "an indispensable prerequisite to a well-paying job and a comfortable life in modern day China" (Sargent et al., 2014, pg. 98). Poor performance on the Zhongkao could result in access to enroll at a less prestigious high school, which could result in enrolling at a less prestigious university. The act of assigning differing values to education and the cycle of fear of inadequacy and underachieving begins at a very young age in the Chinese system.

The societal pressures that students face in the midst of adolescence may be connected to the suicide rates of people between 15-34 in both countries. "Suicide is the leading cause of death for Chinese individuals between the ages of 15 and 34" (Lim, Lim, Michael, Cai, \& Schock, 2010, p. 4) and is the second leading cause of death for Canadians between the same ages (Statistics Canada, 2010). The initial acknowledgement of these findings during this research led to this paper's focus on school pressure and emotional and stress management facilities in schools and communities between both countries.

China's collectivism may have a heavy effect on the social expectations and pressures each student faces in middle schools and high schools. On one hand, the mindset and pressure that students share may enable them to relate to one another; thus, the common goal and drive may reduce individual pressures or stress, as is the opinion of one high school teacher I spoke with. The 
collective pressure and stress contribute to the overall efficiency and drive of the students and teachers.

On the other hand, this pressure seems intimidating at a distance and would warrant a highly structured system of social and academic supports focused on preparing students for stress and maintaining good mental health. It is suggested that, "because of China's centuries-long history of collectivism, the Chinese family and its expanded network have been a bastion against mental health problems" (Lim et al., 2010, p. 4). The individual mental health problems have been restricted to private and familial bounds and hidden from the public. Students are "deeply affected by this culture, a student's academic performance is not simply a personal issue, but also represents the honour and 'glory' ... of his or her family" (Chen et al., 2018, p. 292). The historic respect for education therefore prescribes heavily ingrained importance and expectation on the success and engagement of students, feeding into the desperate necessity to succeed and the fear of poor academic scoring to the point that education is connected to social standing and familial reputation. In China, the avoidance of discussions about mental health may arise from a number of cultural factors. Through an historic scope, "during the Cultural Revolution, psychology and psychiatry were considered counterrevolutionary, bourgeois disciplines that exploited the masses" and therefore "people with mental disorders were released from hospitals and institutions and reeducated with Mao's thoughts" (Lim et al., 2010, pg. 5). Of course, the discipline of psychology was popularized by Freud's focus on wealthy, white women. This notion may have had an effect on the attitudes of the nation, as the interests of bourgeois would not align with the interpretation of Marxist ideologies at the time of the Cultural Revolution. Although, this ideology has fluctuated, and the 1980s brought a strong development of collective identity and support of mental health professionals (Lim et al., 2010).

Canada experienced a similar institutional collapse at the end of the 1960s, and the "lack of effective treatments for patients with mental illness is generally acknowledged to have significantly contributed to the relatively low esteem in which psychiatry was held" (Kirby \& Keon, 2004, p. 137) up until the 1960s. Canada's history of abuse and discrimination toward people with disabilities has profoundly influenced the stigma around mental health facilities and resources. The long line of discrimination against people with mental health disabilities has affected the "sense of inclusion and their ability to exercise their rights," evident through the presence of "insane asylums" in which patients, "once admitted, spent the rest of their lives ... isolated from family and community" (Kirby \& Keon, 2004, p. 137). This sense of isolation has sustained throughout the deinstitutionalization of mental illnesses. The long, shameful history of discrimination and alienation of people with mental illnesses has now inspired ethical methods, research, awareness, and communication in terms of mental health.

Despite its atheist majority, China has high spiritual awareness. Kuan (2008) suggests,

If the education of a child only stresses academic achievement, then the child will inevitably lose many developmental opportunities because this age saves a secure and happy life environment for children who have received education of the heartspirit (xinling) and sensory-emotions (qinggan). (p. 285) 
Although loosely translated and highly-spiritual, this ideology has similar aspects to Western ideas of development, such as those by Erik Erikson and Jean Piaget.

\section{Methodology}

For this paper, research on the available outlets for students' mental health and well-being was conducted by way of a literature review, participant observations, informal interviews with individuals and groups, self-reflective journal entries, and note-taking. Research was triangulated in the form of observation of, and informal interviews about, school climates and atmospheres regarding mental health and students' mental well-being.

\section{Participants}

The participants included multiple students and staff members within one middle school, two high schools, and a university in Chongqing, China. The classes observed included two multidisciplinary 10th grade classes, each containing between forty to fifty students, and two university English language classes, each containing roughly twenty students. Staff members involved were one middle school headteacher, one middle school English language teacher, one middle school guidance counsellor, two university professors, and three university English and journalism students and teacher candidates.

\section{Procedure}

The discussions all involved casual conversations to inquire into the attitudes surrounding the Gaokao, Zhongkao, and mental health. University students who had attended prior schooling (i.e., elementary, middle, and/or high school) either within the Beibei district of Chongqing or otherwise were asked about the preparation techniques they were subjected to by their schools leading up to both national exams, their feelings regarding each experience, and the guidance outlets made available to them.

Two university professors of education who work as supervisors for teacher candidates completing placements in high schools shared about the English fluency of the English majors and non-majors in their first years and beyond, and the process of the Gaokao and Zhongkao. High school and middle school teachers and headteachers talked about their roles in preparing students for the Gaokao, the attitudes surrounding mental health in their school, the Chinese educational system, and their ideas of how students can deal with mental health. One Chinese teacher candidate who was training to become a headteacher talked about the preparation techniques involved in the weeks leading up to the Gaokao.

\section{Findings}

\section{Ontario Tests and Support}

As witnessed in Ontario schools in both the Greater Essex County District School Board (GECDSB) and the Windsor Essex Catholic District School Board (WECDSB), school 
environments offer consistent facilities for academic support, including a guidance room, a staff of guidance support, assemblies for mental health information and stress management techniques, mental health awareness events, and safe spaces to study. Guidance support agents or counsellors are stationed within schools to help students prepare for their futures and manage emotions, time, and stress.

The Education Quality and Accountability Office (EQAO) assessments are conducted most commonly in grades three (math and literacy), six (math and literacy), nine (math), and ten (literacy); however, according to a literacy teacher — who is also the English department head — at one Ontario high school, if a student is sought to do poorly on a test such as the Ontario Secondary School Literacy Test (OSSLT), additional attention is directed into advancing the student's skills, even if that may result in a suggestion to delay the time of writing.

\section{Chinese Schooling and Academic Supports}

The juxtaposition between Canada's seemingly forgiving standardized tests and the rumours of well-disciplined yet highly pressured Chinese students in China sparked my interest. As I travelled throughout China, I found that students fit the stereotypes. High school students on the campus near my host university, as well as the middle school students nearby, resided in dorms within their school campuses. The reason for this was that these were high-level schools, which students travelled great distances to attend. They would have already written their Zhongkao exams, and have been accepted to these schools and others. Their scores on the test unlocked the privilege to attend such campuses.

High school students in the Beibei district were excited to see a foreigner that they could practice their spoken English with. Many shared about their school schedules, which started around 7:30AM, with a two-hour break around 4:00PM, and then continued until around 10:00PM. The students remain in their assigned classroom and the teachers of various subjects rotate, much like the elementary schools in Ontario. In between classes, students have a break to get prepared for the following class, which usually involved taking care of the classroom by cleaning the front board, collecting papers and books, etc. Comparatively, students in Ontario high schools tend to rotate and teachers are more commonly assigned a room. For organizational purposes, students in Ontario are usually given a homeroom; however, they are not restricted to that room for the day.

One major difference between Ontario and Chinese high schools is that in China, each class has a head teacher. The head teacher is responsible for the students within his or her classroom. The principal, and a couple of head teachers suggested to me that their responsibilities include working as a team to attend to mental health needs, but this school in particular did not have a guidance teacher. The principal at the school underwent training and received a certificate in mental health and guidance. Special workshops and home visits play into the way teachers communicate the mental health concerns for a student's well-being. If a child is struggling with a subject area, the teacher will often visit the child's home to discuss that with the parents.

While visiting classes in Beibei district schools, I observed how students were exposed to a considerable amount of mental health reinforcements in the form of visual encouragement (i.e., 
posters) to seek additional mental health assistance available within the school, or from friends or family.

Mr. Z., a teacher at one Beibei district high school, described the way that learning difficulties are often not focused on, are ignored, or are not accepted by parents and teachers (Mr. Z., personal communication, April 21, 2018). He stated that if a student is doing poorly in school, he or she is seen as lazy. He described his role as a head teacher, which includes looking for mood changes and signs of abuse, and talking to individual students who seek emotional assistance in terms of home-life, stress, or other issues. He stated that although he is not a professional psychologist, in his role as a head teacher he assumes the responsibility for his students' mental health and so he must look for physical or emotional symptoms of emotional distress or fluctuations in moods. Chinese homeroom teachers carry a heavy responsibility in terms of student care and "play an important role in psychological counselling of students... which includes moral education, educational and career guidance, personal development, and guidance in interpersonal relationship issues" (Lim et al, 2010, p. 5). This responsibility is connected with the communication outside of the school. Since the majority of students reside on campus, Mr. Z. explained that communication between teachers and parents is necessary and frequent.

The communities play a large part in preparing students for entrance examinations. Mr. Z. admits that the Zhongkao involves an organized system for preparation. Despite this heavy preparation, the focus is more on completing the test rather than effectively teaching students the material or developing oral English skills.

I met with the guidance counsellor, Ms. J., while teaching at a Beibei district middle school. Ms. J. is a trained psychology professional responsible for the mental health of students within her school. Her role is the guidance counsellor or psychology teacher. According to her, all schools in the Beibei district in Chongqing, China have at least one guidance counsellor who is responsible for the mental well-being of students related to stress, home-life issues, depression, anxiety, and preparation for the future (personal conversation, May 18, 2018). In the same school, a counselling room (Xīnlì zìxún shi) was observed; it was a bright, comfortable room decorated with plants, welcoming blue walls, windows, and softly cushioned couches. The waiting room in the main counselling office had a reception desk and couches. This room led into a separate, more secluded room in which individuals may console privately with the counsellor, Ms. J. The set-up of the counselling environment is intended to provide students with a confidential space.

In fact, the entire concept of guidance within the school was intended to cater to confidentiality, as the counselling office was located in a secluded part of the school, away from classrooms, with a stairwell on either side. This location was intended to provide the students with comfort and privacy. Students may therefore feel more inclined to seek assistance if they feel their issues are protected. The counselling office was originally in a more populated area, but moved for confidentiality reasons in order to make students feel more comfortable to visit in the more secluded environment. Students have privacy when travelling to the room and when inside the room. The counselling program is encouraged for student use by invitations from head teachers and posters displayed around the school promoting students' relationships with the guidance counsellor. 
In recent years at Ms. J.'s middle school, an additional transitional room existed in order for students to expel their anger. Among other resources, it contained a punching bag in order to allow students to release built up emotions. This experimental room was opened in 2012, and was accessible only after school. It continued for only two years and was closed when a new school leader started. Schools in Ontario sometimes have a similar transition room or learning support room that is available with supervision for students as an alternative space for class work, however, physical aggression is not encouraged.

Ms. J. described counselling sessions that parents and community members may attend. During our talk, Ms. J. stated that three meetings had been held in the past year, the last held in May of 2018. The meetings are hosted in a nearby primary school and involve parents, school staff, and social workers to help promote mental health. Additionally, all Beibei district schools invite psychologists to give speeches and training to teachers and parents. The meetings involve parent counselling about adolescent behaviour, communication skills between parents and students, and tips on how to relate to students. University psychology professors also host workshops on similar topics on campus and encourage parents to attend. Ms. J. claims that continuing education is available for teachers who seek to gain a special certificate and training in social issues. Those teachers may then organize workshops for other teachers in their own schools to spread awareness. Large meetings are arranged to focus on low-income families, foster families, deceased parents, and stress and emotional management for students (Ms. J, personal communication, May 18, 2018).

In terms of communication, there is an annual group counselling meeting at the beginning of each semester for grades 7-9 in which the counsellor introduces herself, builds encouragement and learning goals, and hosts games and activities in order to build an open and positive environment. Communication is structured within the school between teaching staff and educational psychology professionals. The guidance counsellor is said to communicate with head teachers to discuss what to avoid and what to focus on for specific students, but does not mention specific details. The counsellor is careful to address only the solutions for specific issues, but not the issues themselves, with additional parties. Furthermore, records are never shared between head teachers, administration, or psychological professionals. The counsellor may suggest or encourage further development when needed, and only talks about issues with professionals.

According to Ms. J., all teachers undergo training in basic psychology in order to handle and understand students' issues. Teachers are trained to monitor and refer students to the counsellor if needed. The counsellor will then refer students to university psychologists if needed. Communication is also structured between the school's academic agents and psychological professionals in the community. As a counsellor, Ms. J. has connections with psychologists from Southwest University if problems develop with her student-clients. It is her responsibility to refer students to psychological professionals if she believes further assistance is required.

In terms of preparation, the school community works together to provide students with mock-tests around one month in advance. According to some university students, the Gaokao is such a huge focus in China that the preparation for writing the test causes many other educational aspects to suffer. University students have admitted that only after the Gaokao is completed are 
students able to relax. Once university life starts, students suggest that they can become lazy and careless. This is in opposition to Canadian schooling, in which university seems to be the highest point of pressure. One high school teacher suggests that the time leading up to the Gaokao and Zhongkao are the most crucial times in many Chinese people's lives. The preparation that students undergo seems to be a driving force for the anxiety that students feel, rather than a comforting outlet to dispel anxiety.

Ms. J. described how students are prepared for the Zhongkao in her middle school. One month before testing there is a meeting to help students release stress and to encourage them to talk. They participate in small games to promote relaxation. There is a three-day outdoor trip at the beginning of the semester through which students build relationships with classmates. Ms. J. suggested that peer relationships are very important in order for students to maintain success. There are after school programs established, such as student clubs, ping pong, and arts appreciation. Ms. $\mathrm{J}$. was the main participating organizer until recent years but now other teachers participate as well (Ms. J, personal communication, May 18, 2018).

One teacher candidate suggested that a mock test is performed one month prior to the actual Gaokao exam. Students in younger grades volunteer to organize desks and materials in preparation. The younger grades are then taken on a field trip to vacate a portion of the school for the sake of the exam writers.

According to students, Chinese children are raised with the anxiety of taking the tests. They also have to endure the pressure of the events surrounded by family members, in which parents and security personnel flood the streets not unlike a festival-style setting. On the morning of the Gaokao, the streets around schools can be filled with family members of students. Streets are shut down, and taxis are free for students in order to ensure they arrive on time.

Professors from a Beibei district university were asked about the fluency of English in their English major and non-major students. Both professors agreed that confidence in oral English continues to be lacking, resulting in a cycle of unwillingness to practice. One professor suggested that oral English skills are difficult to develop due to the focus on the written portion of the Gaokao. (personal communication, April 22, 2018).

\section{Discussion}

There is a similar negative stigma against mental health issues in China and Canada. Hence, practices in both countries focus on secluding the counselling areas within schools to avoid embarrassment. Despite this, Beibei district school communities work to dissolve the stigma by encouraging students to visit a school counsellor in order to normalize talking about mental health. At the same time, the process caters to the attitude that mental health should be hidden due to the stigma associated with talking about mental health and concerns. It is a cycle of shame. Although privacy is important, hidden issues are demonized. According to Ms. J., many students still hesitate to act and talk to the counsellor, despite being encouraged by staff members and further attempts made to normalize mental health discussions. She claims that students are embarrassed and assume peers will see them as crazy. I have witnessed this stigma in Canada as well. 
It is important to compare the histories of each country in terms of their attitudes surrounding mental health. How a collective culture views mental health reflects the resources in which mental health solutions arise from. Schools are learning environments that should address curriculum, social development, and emotional management. By examining the historic and ongoing attitudes behind mental health, societies can discover the reasons behind the stigma. School officials and staff have a large responsibility for student development because students are vulnerable. We can better understand the ways in which students struggle and excel by exploring the best available means for schools to use in order to prepare students for stress and emotional development.

Test anxiety in Canada has gained focus over recent years and is recognized to be debilitating in some cases. Standardized testing is in this way criticized for its inaccurate representation of measured learning. Canadian teacher candidates are coached to acknowledge test pressures and student anxiety. They are also encouraged to consider alternative ways of testing. This ideology is rooted in Canadian teachers' focus on differentiated instruction and assessment.

Across schools in Ontario, Canada and Chongqing, China, teachers and guidance counsellors stress that mental health is to be taken seriously. The supports each country enacts to deal with student stress and emotional management seem comparable. However, the divide between these countries' testing methods is vast. China's national tests can be said to cause students intense pressure with questionable educational effectiveness; however, the guidance supports which schools have available seem scarcely more abundant than those found in Ontario's more forgiving education system.

There is a great divide between members of higher and lower classes in China. In my informal interviews, some students and professors have suggested that in rural schools, resources are insignificant and desks may even be made of mud. Class structures and education seem to be entangled in an unforgiving cycle. When poor scoring affects family reputation, one would think that the effects of family standing, home-life, class, and economic factors on the academic success of students would warrant inquiry into social effects on academic success. Rather, academic success seems to represent the family's reputation without significant rationale. Since academic performance so greatly affects the reputation of the family, it can be argued that family and home life have a deep influence on academic success. Where class affects educational success, so too does academia affect the lifestyle of the family, thus perpetuating class.

Lastly, because East Asian immigrants are the largest immigrant population to enter Canada (Statistics Canada, 2017), it is clear that the quality of an educational opportunity is a factor driving students to participate in exchanges. Low scoring students in China can still be successful by travelling to a more forgiving schooling system; this is perhaps one of the greatest influences for migration. After returning to Canada from my teaching placement in China, I had a conversation with a Chinese exchange student attending a school operated by the WECDSB. He claimed that his fear of the Chinese education system led him to participate in the exchange. 


\section{Significance of the Study}

This study encourages educators in both China and Canada to understand the varying levels of preparation taken in regards to mental health, emotional management, and assessment in the two countries. The variety of outlooks between experienced and in-training educators, psychologists, and past and present students allow for a rich understanding of the effectiveness of assessments and the overall educational systems (i.e., understanding what the point of our testing methods are, and what we are actually testing for). By drawing attention to the different styles of education in connection to class and mental health, our societies should acknowledge that there is room for improvement. This research has explored very comparable stigmas towards, and systems for, mental health in schools; however, the difference between systems appears in the process of testing and the effects of poor academic achievement.

\section{References}

Chen, X., Fan, X., Cheung, H. Y., \& Wu, J. (2018). The subjective well-being of academically gifted students in the Chinese cultural context. School Psychology International, 39(3), 291-311. https://doi.org/10.1177/0143034318773788

Kirby, M. J., \& Keon, W. J. (2004). Mental health, mental illness and addiction: Overview of policies and programs in Canada. Ottawa, ON: Senate of Canada. Retrieved October 7, 2018, from https://sencanada.ca/content/sen/Committee/381/soci/rep/report1/repintnov04vol1-e.pdf.

Kuan, T. (2008). Adjusting the bonds of love: Parenting, expertise and social change in a Chinese city (Unpublished doctoral dissertation). Los Angeles, CA: University of Southern California. Retrieved from http://digitallibrary.usc.edu

Lim, S., Lim, B. K., Michael, R., Cai, R., \& Schock, C. K. (2010). The trajectory of counseling in China: Past, present, and future trends. Journal of Counseling and Development, 88(1), 4-8. https://doi.org/10.1002/j.1556-6678.2010.tb00141.x

Sargent, T., Kong, P., \& Zhang, Y. (2014). Home environment and educational transitions on the path to college in rural northwest China. International Journal of Educational Development, 34, 98-109. https://doi.org/10.1016/j.ijedudev.2013.05.003

Statistics Canada. (2010). Leading causes of death. Retrieved October 6, 2018, from http://www.statcan.gc.ca/

Statistics Canada. (2017). Immigrant population by selected places of birth, admission category and period of immigration, Canada, provinces and territories, census metropolitan areas and areas outside of census metropolitan areas. Retrieved October 6, 2018 from https://www12.statcan.gc.ca/census-recensement/2016/dp-pd/dv-vd/imm/index-eng.cfm

$\mathrm{Xu}$. S. (2011). Narrative inquiry in curriculum of life on expanded and extended landscapes in transition. In D. C. Parker, D. Pushor, and J. Kitchen (Eds.), On narrative inquiries into curriculum making in teacher education (pp. 263-280). Bingley, UK: Emerald Group.

$\mathrm{Xu}, \mathrm{S}$. (2017). Cross-cultural schooling experiences of Chinese immigrant families: In search of home in times of transition. London, UK: Palgrave Macmillan.

Xu, S., \& Connelly, F. M. (2008). Narrative inquiry and teacher development. Peking University Education Review, 6(1), 51-69. 
Xu, S., \& Connelly, F. M. (2017). Reciprocal learning between Canada and China in teacher education and school education: Partnership studies of practice in cultural context. Frontiers of Education in China, 12(2), 135-150. https://doi.org/10.1007/s11516-017-0013-6 